\title{
Rhinological Aspects of Endonasal Endoscopic Dacryocystorhinostomy
}

\author{
Karpishchenko $\mathrm{SA}^{1 *}$, Vereshchagina $\mathrm{OE}^{2}$, Baranskaya $\mathrm{SV}^{3}$ and Karpov $\mathrm{AA}^{3}$ \\ ${ }^{1}$ Professor and Chairman of ENT Department, Pavlov First Saint Petersburg Medical State University, Russia \\ ${ }^{2}$ Head of ENT Department, Pavlov First Saint Petersburg Medical State University, Russia \\ ${ }^{3}$ Resident at the ENT Department, Pavlov First Saint Petersburg Medical State University, Russia
}

Submission: March 23, 2018; Published: April 10, 2018

*Corresponding author: Karpishchenko SA, Professor and Chairman of ENT Department, Pavlov First Saint Petersburg Medical State University, Russia, Email: karpischenkos@mail.ru

\section{Abstract}

The endoscopic endonasal dacryocystorhinostomy is a modern and effective surgical treatment of lacrimal pathways obstruction. The leading causes of the unsuccessful outcomes of endoscopic endonasal dacryocystorhinostomy are deviation of nasal septum, concha bullosa and polyps of the nasal cavity.

Purpose: To evaluate the efficacy of endoscopic endonasal dacryocystorhinostomy in primary endoscopic intervention, as well as revision surgery and the frequency of simultaneous surgery of the nasal cavity and paranasal sinus during the endoscopic endonasal dacryocystorhinostomy.

Materials and Methods: A retrospective analysis of clinical data of 159 patients with nasolacrimal duct obstruction, which underwent endoscopic endonasal dacryocystorhinostomy.

Result: In the group of primary operations endoscopic endonasal dacryocystorhinostomy was effective in 148 patients (93\%), in the group of revision surgery was effective in 10 cases $(90 \%)$. A simultaneous operation of the nasal cavity was required in 21 patients.

Conclusion: The experience of our Department shows the high effectiveness of endoscopic endonasal dacryocystorhinostomy in the treatment of patients with nasolacrimal duct obstruction such as in the primary operation and in the revision one. The simultaneous surgery of the nasal cavity allows achieving more optimal results.

Keywords: AS: Acoustic schwannoma; ICA : Internal Auditory Canal; CPA: Cerebellopontine Angle; THS: Tinnitus and Hearing Survey; THI: Tinnitus Handicap Inventory; SOT: Sensory Organization Test; CISS: Constructive Interference Steady State; CT: Computed Tomography

\section{Introduction}

The pathology of the nasal cavity and paranasal sinuses is one of the leading causes of inflammatory diseases of the lacrimal system [1]. The structure of the nasolacrimal canal depends on patient's sex and anatomical features [2]. The close anatomical features of the lacrimal sac, nasolacrimal duct and paranasal sinuses can be a predisposing cause for preventing drainage of tear fluid [3]. When identifying the obstruction of the lacrimal pathways it is important to analyse structure of osteomeatal complex. Also it is necessary to assess the anatomical features of the inferior nasal concha inferior nasal meatus, opening of the nasolacrimal duct and the lacrimal fold (Hasner's valve), severity and location of nasal septal deviation [4].

The dacryocystorinostomy is used to restore the patency of the lacrimal drainage system. Endoscopic endonasal dacryocystorhinostomy is a modern and effective method of treatment of lacrimal pathways obstruction [5]. Endonasal endoscopic dacryocystorhinostomy has the following advantages as absence of external scars, lacrimal pumping mechanism preservation, no damage of medial canthus, less bleeding, possible in the office, may be mixed with correction of associated nasal pathology [6]. The leading causes of the unsuccessful outcomes of endoscopic endonasal dacryocystorhinostomy are the deviation of nasal septum, concha bullosa (also known as middle turbinate pneumatisation) and polyps of the nasal cavity $[7,8]$.

Preoperatively cone beam computed tomography examination with contrasts in order to detect the level of obstruction of lacrimal ducts and identify the anatomical relations between nasal cavity, paranasal sinuses and orbit was performed. We appreciate the state of lacrimal drainage system, 


\section{Global Journal of Otolaryngology}

nasal cavity, paranasal sinuses and the presence of pathological process. All these points contribute to the selection the optimal surgical approach. Also at the preoperative period endoscopy of the nasal cavity is performed to assess the deviation of nasal septal, concha bullosa, nasal polyps and other pathological changes which can be obstacle for endonasal approach to the lacrimal sac Table 1.

Table 1: Summary of Obtained Data.

\begin{tabular}{|c|c|}
\hline Number & 159 \\
\hline Male & $12(7.5 \%)$ \\
\hline Female & $147(92.5 \%)$ \\
\hline Age $(y)$ & $58(18-83)$ \\
\hline Primary dacryocystorhinostomy & $148(93 \%)$ \\
\hline $\begin{array}{l}\text { Revision dacryocystorhinostomy with silicone } \\
\text { tube }\end{array}$ & $11(7 \%)$ \\
\hline Success of primary dacryocystorhinostomy & $137(93 \%)$ \\
\hline $\begin{array}{l}\text { Success of revision dacryocystorhinostomy with } \\
\text { silicone tube }\end{array}$ & $10(90 \%)$ \\
\hline \multicolumn{2}{|l|}{ Simultaneous operations } \\
\hline \multicolumn{2}{|l|}{ - Septoplasty } \\
\hline \multicolumn{2}{|l|}{ - Conchotomy } \\
\hline - Polypectomy & $21(13.2 \%)$ \\
\hline \multicolumn{2}{|l|}{$13(8.2 \%)$} \\
\hline $5(3.2 \%)$ & \\
\hline $3(1.9 \%)$ & \\
\hline
\end{tabular}

\section{Purpose}

To evaluate the efficacy of endoscopic endonasal dacryocystorhinostomy in primary endoscopic intervention, as well as revision surgery and the frequency of simultaneous surgery of the nasal cavity and paranasal sinus during the endoscopic endonasal dacryocystorhinostomy.

\section{Materials and Methods}

A retrospective analysis of clinical data of 159 patients (12 male (7.5 \%), 147 female (92.5\%) with nasolacrimal duct obstruction, which underwent endoscopic endonasal dacryocystorhinostomy in ENT Department of Pavlov First Saint Petersburg State Medical University between January 2013 and January 2017.

In all cases, patients underwent ophthalmologic examination, otorhinolaryngological examination, cone beam computed tomography of the paranasal sinuses and lacrimal pathways with contrast, endoscopy of the nasal cavity that was also used for complete diagnostical examination. In most cases primary surgery was performed under local anesthesia and under general anesthesia in revision cases with stenting. At the primary surgery, the coagulation of a mucous membrane was realized with a diode laser in the contact mode at the first stage (Figure 1). The second step was the lacrimal bone in the projection of the maxillary line, which is also the site of the endonasal projection of the lacrimal sac. The bone was removed by burr. At the third step, lacrimal sac was exposed soft wall and perforated (Figure 1). In the final step, there was a formation of a stable anastomosis between the nasal cavity and the medial wall of the lacrimal sac with usage of mucosal flaps. In the postoperative period, patients were treated with the use of eye drops containing corticosteroids and antibiotics and intranasal topical corticosteroids.

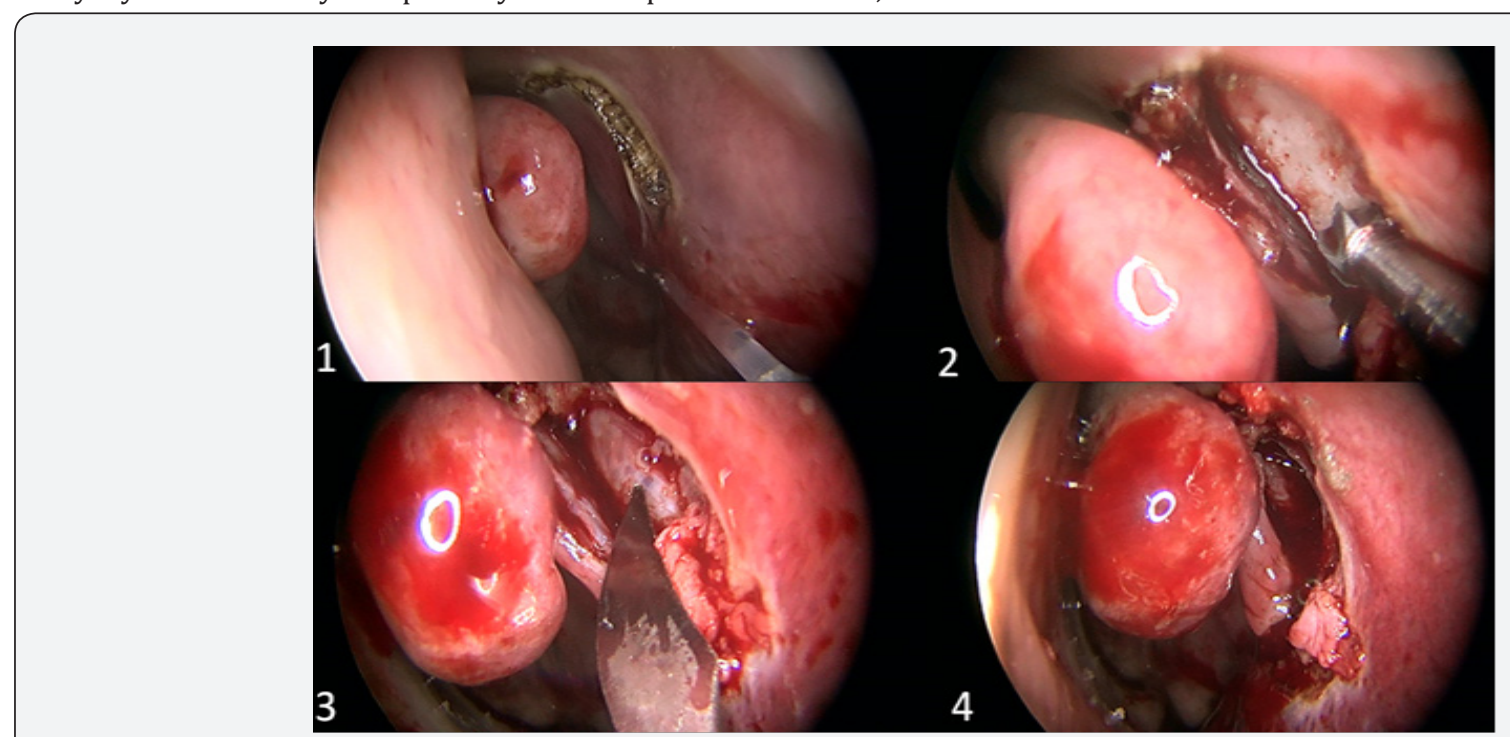

Figure 1: Coagulation of the mucous membrane with a diode laser. 1.2. Removal of lacrimal bone by burr. 1.3. Exposed of lacrimal sac 1.4. Persistent stable anastomosis between the nasal cavity and the lacrimal sac.

For revision surgery, all patients after removal of fibrous or granulation tissue and synechia, using a diode laser in contact mode, a bicanalicular silicone stent was introduced. Fixation of the stent in the nasal cavity was carried out by applying several nodes at the ends of the silicone tubes (Figure 2). In the secondary postoperative period, it was recommended to apply 


\section{Global Journal of Otolaryngology}

the same therapy as after the primary operation. In the presence of pathological features of the nasal cavity of complicated surgical approach, their correction was performed at the same procedure. In cases with a nasal septum deviation, limited septoplasty was performed. In cases with concha bullosa (Figure 3 ), partial middle turbinectomy was performed. Any polyps of the nasal cavity were removed by using a microdebrider. Local anesthesia was quite satisfactory in such cases.

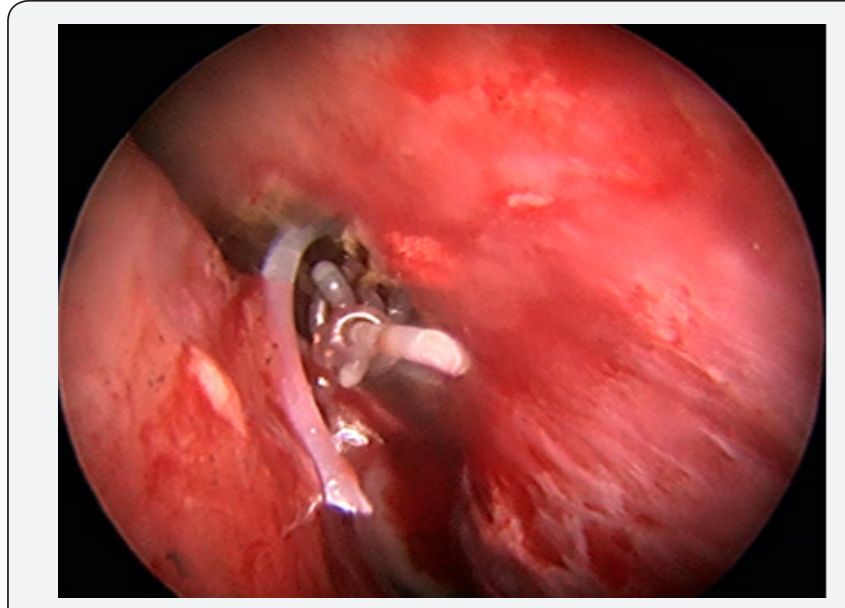

Figure 2: A silicone tube fixed in the left side of the nasal cavity.

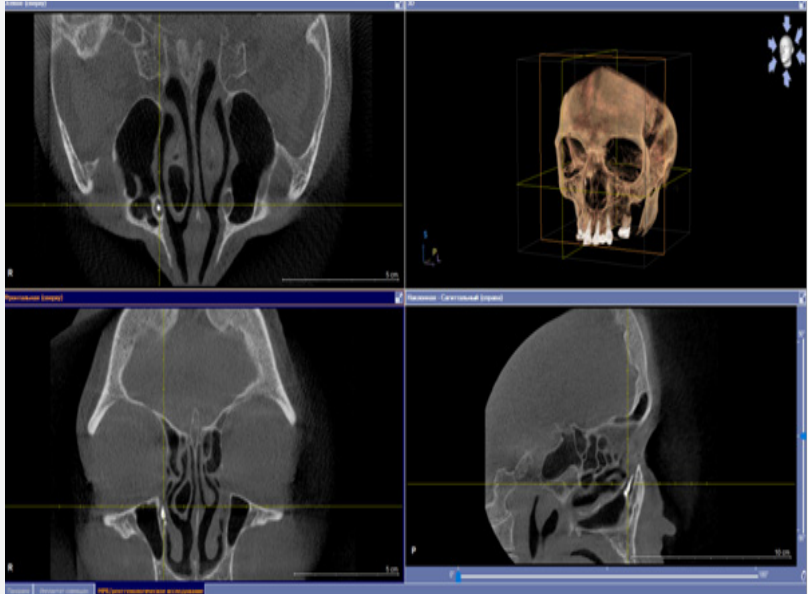

Figure 3: Cone beam computed tomography of paranasal sinuses and lacrimal pathways with contrast. Concha bullosa. Contrast agent in the right lacrimal sac.

\section{Result}

In the group of primary operations, endoscopic endonasal dacryocystorhinostomy was effective in 148 patients (93\%), the follow-up period was 5 months. In $11(7 \%)$ patients revision surgery was necessary.
These patients underwent a revision operation with a bicanalicular silicone tube. The silicone stent was removed 3-6 months after the operation. The follow-up for this group was 3-12 months. No recurrence of stenosis of the nasolacrimal duct was observed in most patients (90\%) in a follow-up. A simultaneous operation on the nasal cavity was required in 21 patients $(13.2 \%)$. Septoplasty was required in 13 cases $(8.2 \%)$, concotomy - in 5 cases (3.2\%), polypotomy - in 3 cases (2\%).

\section{Conclusion}

The experience of our Department shows the high effectiveness of endoscopic endonasal dacryocystorhinostomy in the treatment of patients with nasolacrimal duct obstruction such as in the primary operation and in the revision. It is important to determine the cause of stenosis in patients with an unsuccessful outcome after primary endoscopic endonasal dacryocystorhinostomy and on the basis of these data, choose a revision surgical method, which can improve the final successful rate of the operation. The simultaneous surgery of the nasal cavity allows achieving more optimal results, as well as preventing the development of stenosis in anastomosis and the development of relapse of disease. Local anesthesia increases the availability of surgical procedure for many patients.

\section{References}

1. Wong RJ, Gliklich RE, Rubin PA, Goodman M (1998) Bilateral nasolacrimal duct obstruction managed with endoscopic techniques. Arch Otolaryngol Head Neck Surg 124(6): 703-706.

2. Shigeta K, Takegoshi H, Kikuchi S (2007) Sex and age differences in the bony nasolacrimal canal: An anatomical study. Arch Ophthalmol 125(12): 1677-1681

3. Onerci M (2002) Dacryocystorhinostomy. Diagnosis and treatment of nasolacrimal canal obstructions. Rhinology 40(2): 49-65.

4. Karpishchenko SA, Beldovskaya NY, Baranskaya SV, Karpov AA (2017) Ophthalmic complications of functional endoscopic sinus surgery. Ophthalmology Journal 10(1): 87-92.

5. Karpischenko SA, Baranskaya SV (2016) Our experience in intranasal laser endoscopic dacryocystorhinostomy / Folia Otorhinolaryngologiae et Pathologiae Respiratoriae 22(3): 32-35.

6. Sham CL, van Hasselt CA (2000) Endoscopic terminal dacryocystorhinostomy. Laryngoscope 110: 1045-1049.

7. Elmorsy SM, Fayk HM (2010) Nasal endoscopic assessment of failure after external dacryocystorhinostomy. Orbit 29(4): 197-201.

8. Demarco R, Strose A, Araújo M (2007) Endoscopic revision of external dacryocystorhinostomy. Otolaryngol Head Neck Surg 137(4): 497-499. 
(C) Commons Attribution 4.0 License BY DOI: $10.19080 / G J O .2018 .14 .555895$
Your next submission with Juniper Publishers will reach you the below assets

- Quality Editorial service

- Swift Peer Review

- Reprints availability

- E-prints Service

- Manuscript Podcast for convenient understanding

- Global attainment for your research

- Manuscript accessibility in different formats

( Pdf, E-pub, Full Text, Audio)

- Unceasing customer service

Track the below URL for one-step submission https://juniperpublishers.com/online-submission.php 